\title{
Entonces te quedas así como que... Análisis sintáctico-pragmático de la partícula como en una hablante de Caracas
}

\author{
"Entonces te quedas así como que..." \\ Syntactic-pragmatic analysis of the particle "como" in a Caracas speaker
}

Leonardo Andrés Aguilar Durán

Universidad Pedagógica Experimental Libertador, Venezuela

\section{Resumen}

Este artículo reporta los resultados de una breve experiencia investigativa que tuvo como objetivo explorar las funciones sintáctico-pragmáticas de la partícula como en el lenguaje oral e informal de una joven de Caracas. Hasta ahora, el análisis integral de la partícula objeto de atención solo se había realizado en la variedad formal y escrita del español de Venezuela. Se trató de un estudio lingüístico descriptivo de corte sincrónico. La informante fue una adolescente de 17 años de edad, bachiller, perteneciente a la clase media. Predominó el sentido aproximativo de como, tanto en su forma más típica como en el matiz aproximativo del cual están impregnadas las funciones de citación, atenuación, comparación hipotética y planificación del discurso. A la presentación de resultados sigue la discusión teórica de los usos hallados y el planteamiento de algunas consideraciones respecto a la suficiencia de las categorías que en la literatura se manejan. Si lo que se desea es elaborar una taxonomía del comportamiento ostentado por como en el habla venezolana, futuros estudios tendrían que trabajar con una muestra amplia y segmentarla.

Palabras clave: sintaxis, pragmática, partícula como, habla juvenil, español de Venezuela

\begin{abstract}
This article reports the results of a brief research experience that aimed to explore the syntactic-pragmatic functions of the particle like in the oral and informal language of a teenage woman from Caracas. Until now, the integral analysis of the particle object of attention had only been made in the formal and written variety of the Spanish of Venezuela. It was a descriptive linguistic study of a synchronic nature.
\end{abstract}


The informant was a 17-year-old female teenager, with high school completed, that belonged to the middle class. The uses of like with approximative sense have predominated, in its most typical form and as part of the functions of citation, attenuation, hypothetical comparison and discourse planning. The presentation of results is followed by the theoretical discussion of the uses found and by some considerations regarding the sufficiency of the categories reported in the literature. If what matters is the elaboration of a classification to characterize the behavior of like in Venezuelan speech, future investigations would have to expand and segment the sample.

Keywords: syntax, pragmatics, particle like, youthful speech, Spanish from Venezuela

\section{Introducción}

$\mathrm{T}$ al como lo señala Escandell (1996), en la lengua, hay fenómenos a los cuales la sintaxis pareciera no poder darles una respuesta definitiva, pues, más allá de cualquier explicación funcional brindada, se trata de construcciones que están marcadas por las interacciones y los intereses comunicativos de los hablantes. Son más bien estructuras que se prestan a un análisis desde la semántica, la pragmática o la combinación de ambas (Villegas, 2011). Por tal razón, al no poder ser explicadas bajo un único enfoque, dan pie a controversia entre los estudiosos de la lingüística.

Este es el caso de la palabra como, partícula objeto de estudio en el presente trabajo, la cual cumple diferentes funciones desde el punto de vista sintáctico e, incluso, se presta a variadas interpretaciones semánticos, pragmáticos y discursivos. Es una palabra que ha generado polémica entre los lingüistas puesto que, si bien es cierto que desde hace tiempo ha podido ser clasificada en distintas categorías, no hay acuerdo en cuanto a la manera de explicar la variedad de usos que puede tener.

La perspectiva funcional ha clasificado a como en diferentes categorías gramaticales, como los adverbios relativos de modo o las conjunciones. Sin embargo, dependiendo de los criterios de análisis empleados por el autor que la aborde, una misma construcción puede ser reportada como adverbial o conjuntiva. Además, aun cuando existen usos de como que pueden ser explicados a partir de un análisis estructural, hay casos en los que la explicación a la luz de criterios sintácticos y gramaticales no resulta enteramente satisfactoria, exigiendo ser comprendidos desde un abordaje semántico o pragmático.

Al panorama descrito se le suma el hecho de que los estudios dedicados al tratamiento de la palabra como (e.j., Holmvik, 2011; Jørgensen y Stenström, 2009; Yao, 2008) tienden a limitarse a describir sus usos en la variedad peninsular del español, dejando de lado otras variedades. Es en este contexto que cobra relevancia la investigación de Rivas (2016), 
la cual se propuso describir los usos de como en artículos de opinión venezolanos de los siglos XIX y XXI, siendo además el único trabajo que se ha ocupado de ello en el español de Venezuela, exceptuando algunos acercamientos parciales/tangenciales al estudio de tales usos discursivos (e.j., Marcano, 2007a, 2007b; Zabalegui, 2015).

La primera fase de la investigación antedicha consistió en la revisión bibliográfica, con el fin de conocer y analizar el material disponible acerca de los usos de como. Si bien la autora consideró la posición de diversos autores, el énfasis estuvo en la propuesta teórica de la Real Academia Española (2010), puesto que, además de constituir el aporte más reciente respecto al tema de interés, recogía en ella mucho de lo ya explicado por autores previos. El segundo paso fue la selección del corpus: por el siglo XIX se trabajó con el periódico El cojo ilustrado, mientras que en el caso del siglo XXI se tomaron artículos de los diarios El Nacional y Últimas Noticias. Posteriormente, tomando como referencia la bibliografía clásica y moderna sobre el tema, se procedió a la elaboración de una serie de criterios con el fin de diseñar una taxonomía que permitiera realizar una clasificación, lo más objetiva y homogénea posible, de los enunciados en los que participa la partícula como.

Las construcciones se dividieron en dos grandes paradigmas. El primero de ellos corresponde a aquellas en las que los criterios de interpretación se consideran exclusivamente formales o sintácticos. Abre este grupo la conjunción subordinante, que puede ser comparativa (con cuantificador tácito, con cuantificador expreso tan y tanto, sin cuantificador y la pauta así... como), causal (canónica, pospuesta, con subjuntivo y la pauta como tal), condicional y completiva; en segundo lugar, el adverbio relativo, ya sea introduciendo estructuras con antecedente expreso, introduciendo oraciones relativas libres, en incisos nominales (algunos de los cuales tienen un antecedente adverbial expreso) y la pauta tan... como; en tercer lugar, está la preposición, la cual se clasifica según su capacidad de conmutación (conmutable y no conmutable), en función de las estructuras sintácticas en las que sirve de encabezador (introductor de complemento predicativo, introductor de atributo y no introductor de los anteriores) y según los verbos a los cuales está asociada (con verbos de habla, percepción o juicio; y con otros verbos); finalizan el grupo todas aquellas estructuras cuya explicación gramatical resulta suficiente para comprender su comportamiento.

El segundo grupo quedó constituido por aquellas construcciones en las que es imposible desligar los aspectos sintácticos de los inherentes a la interacción, es decir, los elementos discursivos. Tales estructuras se denominaron sintáctico-pragmáticas (ver Anexo para conocer los criterios de clasificación); son casos en los que como puede aparecer en calidad de ejemplificativo, locución conjuntiva exceptiva, marcador de indiferencia (la pauta verbo subjuntivo + como + verbo subjuntivo), introductor de negación enfática, introductor de enunciados aproximativos y atenuador. Por su parte, la pauta como que puede calificar como locución conjuntiva, introductor aproximativo, ejemplificativo, conjunción continuativa y locución conjuntiva causal. La pauta como si puede considerarse en calidad de locución conjuntiva, 
introductor de comparación hipotética e introductor negativo fuerte. La pauta como para puede ser interpretada como aproximativo, marcador de intensidad continuativa y cuantificador evaluativo; cierran el grupo las pautas como mucho en calidad de aproximativo y así como en calidad de introductor de oraciones temporales. Vale destacar que la partícula como en sentido aproximativo se puede presentar en cuatro casos diferenciados, a saber: (a) cuando no se tiene certeza sobre el nombre de un objeto o sobre la veracidad de un enunciado, (b) para presentar una cantidad como aproximada, (c) para presentar una hora o fecha como aproximada y (d) en estructuras en las que el hablante manifiesta imprecisión en la expresión empleada.

Es importante señalar que la investigación determinó que el número de enunciados que se prestó a interpretación pragmática aumentó durante el siglo XXI, hecho que da cuenta, por un lado, de los versátiles usos de esta partícula desde el punto de vista discursivo y, por otro, de su frecuente empleo en la actualidad.

En muchos casos, las construcciones formadas con la partícula como en el corpus analizado respondieron a los postulados esbozados sobre el tema en la bibliografía canónica. Sin embargo, un número no desdeñable de enunciados dejaron de ceñirse a los usos más tradicionales de esta palabra, siendo necesario en estos casos elaborar algunos criterios o modificar los ya existentes para poder darles explicación. De modo que haber encontrado estructuras con como no explicadas o insuficientemente explicadas en la bibliografía, sugiere que en alguna medida varias de ellas exhiben un comportamiento particular en el español de uso en Venezuela.

Rivas (2016) considera que su trabajo constituyó apenas una aproximación a los usos de como y juzga pertinente el emprendimiento de estudios a través de los cuales se intente dar respuesta a diversos aspectos inherentes al comportamiento de esta partícula. En atención a ello, el propósito de este trabajo será analizar desde el punto de vista sintáctico-pragmático los usos de la partícula como en una hablante de la ciudad de Caracas. A partir de lo anterior, se espera lograr una aproximación a las funciones predominantes de dicha partícula, esta vez en la oralidad, y reflexionar acerca de la pertinencia de la bibliografía disponible para dar cuenta de los usos detectados en el lenguaje oral. En suma, por haber permitido conocer los valores pragmáticos de como para el caso del español venezolano, se reconoce en la investigación de Rivas (2016) el antecedente fundamental del estudio que ahora se presenta concentrándose en el lenguaje utilizado de forma oral.

Se ha aseverado que, desde una perspectiva gramatical normativa, la lengua constituye una unidad, pues se trata de un conjunto de signos y reglas comunes; en cambio, desde el punto de vista de la realización de la lengua por parte de los usuarios, esta no es uniforme (Bernárdez, 1999; Blas, 2005). Precisamente, el ámbito de la oralidad es el terreno donde la afirmación hecha puede encontrar su mayor asidero. De acuerdo con Parra (2004), el texto oral -a diferencia del escrito- permite el uso de palabras y expresiones nuevas y coloquiales con poca censura social, además de poseer, en general, un estilo más sencillo y espontáneo, características que entroncan con el segundo 
aspecto que este estudio pone bajo lupa: la variedad lingüística de los jóvenes.

Más allá de experimentar obvias variaciones según condiciones pragmáticas y sociolingüísticas, el lenguaje juvenil tiene rasgos particulares y un estilo comunicativo especial, por ejemplo: el uso frecuente de marcadores del discurso y las llamadas palabras tabúes (Jørgensen y Martínez, 2007; Navdal, 2007; Rodríguez, 2002). Además Zimmermann (2002) destaca su función identitaria, de allí que a menudo este grupo etario intente distinguirse de los demás por su forma de expresarse (Briz, 2003; Rodríguez, 2002).

Con frecuencia, el lenguaje típicamente juvenil es valorado de forma prejuiciada por ser sumamente desembarazado, así como por abundar en vocabulario coloquial, gramática errónea, articulación deficiente y muletillas (Herrero, 2002; Lázaro, 1980); estas últimas expresiones consideradas por el común de la gente como "palabras de relleno" que "empobrecen" el discurso $\mathrm{y}$, por lo tanto, deberían evitarse. A pesar de la crítica, según varios lingüistas, los jóvenes son quienes más influyen en los cambios que la lengua experimenta, razón por la que vale la pena estudiar este lenguaje (Andersen, 2001; Briz, 2003; Herrero, 2002; Jørgensen y Stenström, 2009; Rodríguez, 2002; Zimmermann, 2002). En vez de condenar el lenguaje utilizado por los jóvenes, habría que prestar atención a los cambios que en él tienen lugar y que, con el tiempo, terminarán influyendo sobre la lengua de los adultos. Siendo así, el uso de como en el lenguaje juvenil actual puede ser un indicador de su uso futuro entre los adultos.

Sobre la base de los planteamientos expuestos, destaca la relevancia y pertinencia de llevar a cabo un estudio local que permita explorar los diversos usos hablados de como a la luz de novísimas consideraciones teóricas. Aunque debido a razones metodológicas la información que se obtenga posea un escaso valor de generalización, su valor heurístico sí está asegurado: se puede conocer en mayor medida el comportamiento del fenómeno lingüístico en consideración, se revisa la utilidad del modelo de análisis de Rivas (2016) y se apuntan ideas y recomendaciones para futuras investigaciones.

\section{Método}

Tipo y diseño de investigación. El presente es un estudio lingüístico descriptivo. La investigación descriptiva busca caracterizar cualquier fenómeno que se analice (Hernández, Fernández y Baptista, 2014), y este constituyó precisamente el objetivo del trabajo respecto al fenómeno objeto de interés, que en este caso fue el estudio exhaustivo de los usos funcionales de como en una hablante de Caracas. Así mismo, sigue un diseño transversal, ya que los datos se recolectaron en un momento único, lo que constituye una aproximación sincrónica al estudio del lenguaje.

Informante. Se trata de una adolescente de 17 años de edad, natural de Caracas (Venezuela), quien toda su vida (salvo viajes breves y esporádicos) ha tenido por lugar de residencia la Parroquia Caricuao, Municipio Libertador, de la ciudad capital. Pertenece al estrato socioeconómico III (clase media). Para el momento en que fue contactada, acababa de finalizar la educación media y se encontraba a la espera de iniciar estudios 
universitarios. La participante no posee ninguna discapacidad.

$\mathrm{Su}$ núcleo familiar está conformado por su madre, de 42 años, oriunda del Edo. Barinas, es Técnico Superior Universitario (TSU) y labora en el área de recursos humanos; su padre, de 48 años, natural del Edo. Bolívar, es bachiller y trabaja como electricista; y su hermano, de 9 años, es caraqueño y cursa $4{ }^{\circ}$ grado de educación primaria.

\section{Materiales}

Hoja de datos sociodemográficos. En esta hoja se contempló información reportada por la informante acerca de sí misma (i.e., sexo, edad, lugar de nacimiento, lugar de residencia, nivel de instrucción, rendimiento académico, ocupación y reporte de alguna discapacidad) y sobre los miembros de su grupo familiar (i.e., edad, lugar de procedencia, nivel educativo y ocupación). Los datos obtenidos permitieron la caracterización de la participante que aparece en el apartado anterior.

Formato de estratificación social. Para la identificación del estrato socioeconómico de la familia de la joven estudiada, se aplicó el Método de Estratificación Social Graffar-Méndez Castellano (MGMC; Méndez Castellano y Méndez, 1994). Con este se obtienen cinco estratos sociales, el I corresponde a las mejores condiciones socioeconómicas y el $\mathrm{V}$ a las de mayor vulnerabilidad. Con más detalle, el estrato I o clase alta, el estrato II o clase media alta, el estrato III o clase media, el estrato IV o clase obrera (también denominado estrato de pobreza relativa) y el estrato $\mathrm{V}$ o clase baja (de pobreza crítica y estructural).
El estrato social se obtiene al sumar los puntajes alcanzados en cada una de las cuatro variables que conforman el método, a saber: profesión del jefe de familia, nivel de instrucción de la madre, principal fuente de ingreso y tipo de vivienda.

Guión de entrevista. Previo al encuentro con la informante se hizo necesario elaborar una guía de entrevista con preguntas "rompehielo", interrogantes referidas a diversas áreas (i.e., personal, académica o estudiantil, familiar, de pareja, social y/o recreativa, alimentación y salud física), otras que planteaban diversos temas sobre los cuales se pedía fijar opinión (e.j., la situación política del país, el aborto, las drogas, la guerra, el racismo, la homosexualidad) y un grupo final de misceláneas y curiosidades. El investigador asumió esta guía temática, no como una lista estructurada de preguntas, sino como una pauta flexible que servía para orientar la conversación y podía ser modificada sobre la marcha, pues era la entrevistada quien daba forma al discurso con sus comentarios.

\section{Procedimiento}

La informante fue contactada sobre la base de los siguientes criterios: que fuese adolescente, que tuviese por lugar de nacimiento, crianza y residencia el Municipio Libertador del Distrito Capital, que no tuviese ningún grado de consanguinidad o afinidad con el entrevistador (de hecho, no se conocieron sino hasta el momento de la entrevista) y que no presentara dificultades de comunicación y comprensión.

Por tratarse de una chica menor de edad, además de su autorización para ser entrevistada y grabada, se obtuvo 
el consentimiento informado de su representante legal. Dada la naturaleza de esta investigación, no se estimó conveniente que la informante estuviese al tanto del objetivo, por lo que este le fue presentado como el de conocer el estilo de vida de los jóvenes caraqueños y sus opiniones con respecto a diversos temas de actualidad; al finalizar la recogida de datos, se le informó el verdadero propósito del estudio. Huelga decir que se guardó observancia de los aspectos éticos referidos al anonimato y la confidencialidad de la información.

Se llevó a cabo una entrevista semiestructurada mediante el guión previamente descrito. La entrevista tuvo una duración de $1 \mathrm{hr}, 3$ min y $49 \mathrm{~s}$; se realizó en el domicilio de la informante, con quien se procuró conseguir rapport y generar un clima de confianza. En tal sentido, lejos de discutir sus puntos de vista o de expresar alguna actitud evaluativa ante ellos, se mostró interés en lo que la joven dijo o narró.

La entrevista fue transcrita a fin de organizar y analizar los datos resultantes. El proceso de transcripción se realizó con apego a las instrucciones señaladas por Flores (1991, pp. 76-79). En caso de interrupciones forzosas, comentarios generales o indicaciones de lenguaje gestual se utilizan corchetes intercalados en los parlamentos de la informante para incluir las explicaciones pertinentes en mayúsculas, de esta manera: [ESPECIFICACIÓN DE LO SUCEDIDO]. Cuando existe un rasgo lingüístico o una pronunciación que se quiere resaltar, se coloca entre corchetes la expresión latina "[SIC]", para señalar que lo anterior a ella es exactamente lo que se ha querido escribir.

En cuanto al procedimiento de análisis, se realizó una revisión exhaustiva de la entrevista transcrita con el fin de extraer aquellos enunciados en los que participara la partícula estudiada, excluyéndose los usos puramente interrogativos y exclamativos de cómo, al igual que sus usos formales o estrictamente sintácticos. Tras sustraer todos los enunciados en los que como cumplía una función de carácter sintáctico-pragmático, se procedió a analizarlos a la luz de la taxonomía elaborada para tal fin por Rivas (2016), consiguiéndose así una categorización de las diferentes estructuras halladas. Es pertinente señalar que cuando se identificaron estructuras en las cuales la palabra como participaba más de una vez, se valoró el uso que correspondía a cada una de estas apariciones y, en consecuencia, se clasificaron en el paradigma que fuese pertinente. Dicho de otra manera, era posible que en un mismo enunciado apareciera dos veces la partícula como, en cuyo caso eran clasificadas en dos categorías separadas si respondían a usos funcionales distintos.

Sobre la base de la taxonomía referida (ver Anexo para consultar criterios de clasificación), en el apartado correspondiente a los resultados, se expone el comportamiento sintáctico-pragmático de la partícula objeto de análisis a partir de varios registros de frecuencias y se comentan cada uno de los usos de como reportados por la informante. Por último, se discute si los usos registrados en la bibliografía sobre el tema realmente pueden explicar los que fueron encontrados mediante el análisis de la entrevista, lo que termina de dar respuesta al objetivo del estudio.

\section{Resultados}

La partícula como apareció 170 veces en la transcripción de la entrevista. 
Tras haber excluido los usos exclamativos, interrogativos, verbales (i.e., del verbo comer) y aquellos que había pronunciado el entrevistador mientras la informante intervenía, el repertorio se redujo a 114 enunciados en los cuales la palabra como apareció en 143 ocasiones.

Como puede apreciarse en la tabla 1 , se identificaron 17 oportunidades ( $12 \%$ del total de apariciones) en las que como tuvo un uso que pudo ser explicado a partir de criterios meramente sintácticos. En tales casos, la mayor de las veces como actuó a modo de conjunción comparativa (e.j., "la verdad es que no ser como ella, sino ser mejor que ella") y causal (e.j., "y yo como estaba dolida [...] me fui con él"), también como adverbio relativo (e.j., "me gusta mucho tratar como me traten") y, en un par de ocasiones, tuvo un uso preposicional (e.j., "hay profesores que fueron como mis padres").

\section{Tabla 1}

\section{Registro de frecuencias para los usos exclusivamente sintácticos de la partícula como}

\begin{tabular}{|c|c|c|c|}
\hline & \\
\hline & $\mathbf{f}$ & $\% \mathrm{~A}$ & $\% \mathrm{~B}$ \\
\hline \multicolumn{4}{|c|}{ Conjunción subordinante } \\
\hline Conjunción comparativa & 5 & 29.4 & 62.5 \\
\hline Conjunción causal & 3 & 17.6 & 37.5 \\
\hline Subtotal & 8 & 47.0 & 100.0 \\
\hline Adverbio relativo & 7 & 41.2 & 100.0 \\
\hline Preposición & 2 & 11.8 & 100.0 \\
\hline Total & 17 & 100.0 & \\
\hline
\end{tabular}

Nota: \% A= porcentaje con respecto al total de usos sintácticos. \% B = porcentaje con respecto a la subclase respectiva.

En cambio, en 126 apariciones (88\% del total) contenidas en 101 estructuras, como hubo de ser analizado a partir de principios sintácticos y pragmáticos concatenados. En la tabla 2 es posible observar que, en estos casos, predominó el uso de la partícula como (a secas) y de la pauta como que (54\% y 45\%, respectivamente).
La aproximativa fue la función pragmática más utilizada (81\%), el 19\% restante se divide entre la locución conjuntiva (que, de por sí, tiene un sentido aproximativo), la atenuación, la comparación hipotética y otros usos no considerados por Rivas (2016) sobre los cuales se tendrá a bien volver más adelante. 
Tabla 2

Registro de frecuencias para los usos sintáctico-pragmáticos de la partícula como

\begin{tabular}{|c|c|c|c|}
\hline & \\
\hline & f & $\% \mathrm{~A}$ & $\% \mathbf{B}$ \\
\hline \multicolumn{4}{|l|}{ Como } \\
\hline Aproximativo & 57 & 45.2 & 83.8 \\
\hline Atenuador & 2 & 1.6 & 2.9 \\
\hline No determinado (vacilación) & 9 & 7.1 & 13.2 \\
\hline Subtotal & 68 & 53.9 & 100.0 \\
\hline \multicolumn{4}{|l|}{ Como que } \\
\hline Locución conjuntiva & 3 & 2.4 & 5.3 \\
\hline Aproximativo & 45 & 35.7 & 78.9 \\
\hline No determinado (vacilación) & 9 & 7.1 & 15.8 \\
\hline Subtotal & 57 & 45.2 & 100.0 \\
\hline \multicolumn{4}{|l|}{ Como si } \\
\hline Introductor de comparación hipotética & 1 & 0.8 & 100.0 \\
\hline Total & 126 & 100.0 & \\
\hline
\end{tabular}

Nota: \% A = porcentaje con respecto al total de usos sintáctico-pragmáticos. \% B = porcentaje con respecto a la subclase respectiva (e.j., como que).

La condición sine qua non para reconocer el uso aproximativo de como es cuando, a través de esta partícula, el hablante desea presentar su enunciado como hipotético, como una idea producto de una percepción personal que no necesariamente debe ajustarse a la realidad y mucho menos ser compartida por el otro (Rivas, 2016).

La tabla 3 permite apreciar que la imprecisión en la expresión y la introducción de citas (un uso no reportado por Rivas, 2016) se dividieron la presentación de casos aproximativos; como preponderó en las imprecisiones y como que prevaleció para la citación. Usos más tradicionales de la aproximación a partir de como (i.e., cantidad, hora o fecha aproximada) no se observaron. Las pautas como para y como mucho no registraron usos aproximativos. 
Tabla 3

Registro de frecuencias para los usos de la partícula como en sentido aproximativo

\begin{tabular}{|c|c|c|c|}
\hline & \\
\hline & f & $\% \mathrm{~A}$ & $\% \mathrm{~B}$ \\
\hline \multicolumn{4}{|l|}{ Como } \\
\hline Imprecisión en la expresión & 52 & 51.0 & 91.2 \\
\hline Indeterminado (introductor de cita) & 5 & 4.9 & 8.8 \\
\hline Subtotal & 57 & 55.9 & 100.0 \\
\hline \multicolumn{4}{|l|}{ Como que } \\
\hline Imprecisión en la expresión & 9 & 8.8 & 20.0 \\
\hline Indeterminado (introductor de cita) & 36 & 35.3 & 80.0 \\
\hline Subtotal & 45 & 44.1 & 100.0 \\
\hline Total & 102 & 100.0 & \\
\hline
\end{tabular}

Nota: $\% \mathrm{~A}=$ porcentaje con respecto al total de usos aproximativos. $\% \mathrm{~B}=$ porcentaje con respecto a la subclase respectiva (e.j., como que).

A continuación se presentan las pautas formadas con como en las que la hablante manifiesta imprecisión en cuanto a la expresión empleada:

(1) uno conoce muchas cosas nuevas, uno se abrecomo... a muchos círculos sociales

(2) y... vas como conociendo como la realidad de lo que realmente es el mundo

(3) y... vas como conociendo como la realidad de lo que realmente es el mundo

(14) dar como lo que recibes

(16) no me gustan los problemas porque me pongo en un estado de ánimo bastante, como que siempre pienso en eso y no puedo enfocar

(17) soy una persona a veces bastante como que se deja llevar mucho por los sentimientos siempre trato como de estar con una sonrisa para los demás

(21) las personas que yo realmente he querido y quiero muchísimo es a (...) Kevin que es como mi novio exnovio

(24) cuando no hay nadie tú te aferras a ese dios y es como un apoyo para levantarte

(25) a lo mejor estás solo pero tú sientes que no estás solo en ese momento, es como tenerte a ti mismo pero de otra manera 
(28) para mí el liceo fue como una etapa de crecer

(30) ese [sIc] fue como mi materia favorita en todos los años

(34) a mí siempre me ha costado mucho hacer amigos no sé por qué, es como que, es como de herencia porque mi mamá también

(43) cuando salía era como a jugar fútbol y a echar broma

(51) él veía las cosas como que... muy [HACE SONAR LOS DEDOS CONTRA LA MESA]... cómo se dice, muy... como a su manera, muy directas, muy malas

(58) la costumbre es algo... es como una rutina, es como estás acostumbrado a verlo todos los días, hablar con él todos los días

(59) después te sientes como un vacío

(60) estoy horita [SIC] como en esa lucha como de ajá Andrea [CHAsQUEA LOS DEDOS] iprepárate!

(65) y a veces (...) [el] ser humano se... como que se deja llevar mucho por las situaciones y no toma bien decisiones

(73) siempre por eso tengo como mis dos amigas

(76) siempre encuentro como una manera de entrarle a las personas, isiempre!, es alg... jes como un don que tengo!

(79) si tú estás con una persona que no estudia tú... de repente como que haces la tarea, la broma, y él como que jay!, marico no hagas eso, vamos a hacer algo

(83) todavía no me siento preparada para eso, porque es algo como que tú llegas y tú ¡Ay, estoy cantando frente a todo el mundo, no!

(89) cayeron en un pozo de leche, era como una olla
(91) siempre me ha gustado como se... yo siento que tengo como ese lado interior al que quiero ir a todos lados y adentrarme y quedarme en la selva

(93) me gusta mucho porque es un mensaje muy lindo, es como toda una vaina, muy mariquita

(95) estoy como viendo televisión y como, y a veces como que papá te quedó rico el arroz, ah, sí, gracias [REMEDANDO A SU PAPÁ]

(100) todo esto me da como ganas de llorar porque es que yo quiero muchísimo a mí país

(102) es como parte buena y... tiene sus dos partes

(123) Ehm... como trabajar, o sea, tener como un medio económico para ayudarme...

(124) )Ehm... como trabajar, o sea, tener como un medio económico para ayudarme...

Refiere Rivas (2016, p. 152) una condición aproximativa en la cual "El hablante desea alejarse de su proposición, fundamentalmente porque no tiene la información suficiente para comprometerse con la veracidad del enunciado". Agrega que esto casi siempre sucede "cuando el hablante no tiene conocimiento sobre el nombre exacto del objeto al cual hace referencia" (p. 152). Al momento de analizar los enunciados extraídos de la transcripción, en varias oportunidades, resultó confuso distinguir la condición descrita de las estructuras en las que la hablante denota imprecisión en la expresión empleada, si bien la decisión final decantó en estas últimas. La tabla 4 presenta la estadística de los casos de duda. 
Tabla 4

Registro de frecuencias para los usos aproximativos de la partícula como cuya subclasificación resulta confusa

\begin{tabular}{lcccc}
\cline { 2 - 4 } & $f$ & $\% \mathrm{~A}$ & $\% \mathrm{~B}$ & $\% \mathrm{C}$ \\
\hline Como & 16 & 84.2 & 28.1 & 15.7 \\
& 3 & 15.8 & 6.7 & 2.9 \\
& 19 & 100.0 & 34.8 & 18.6 \\
\hline
\end{tabular}

Nota: $\% \mathrm{~A}=$ porcentaje con respecto al total de usos aproximativos confusos. $\% \mathrm{~B}=$ porcentaje con respecto a la subclase respectiva (e.j., como que) de usos aproximativos. \% $\mathrm{C}=$ porcentaje con respecto al total de usos aproximativos.

Parece que la confusión mencionada se presenta debido a que en la mayoría de estos casos pudiera haber un mejor término, uno más adecuado desde el punto de vista prescriptivo, para conseguir una construcción oracional formal. Además, varias veces se acude a términos de interpretación figurada: encajar $=$ llevársela bien $(53,54)$, escape $=$ distracción de los problemas $(66,67)$, ver $=$ experimentar (71), lucha interna $=$ conflicto personal (113) y chocar $=$ discrepar de alguien (114). En otros casos parece que la hablante duda del término empleado: "hinchada" (97), "[una] presión" (105), "evaluar[los] psicológicamente" (117) y "empresario" (122). Resta señalar la mención del vocablo "yoísta", referido a una persona egoísta y/o egocéntrica, el cual, sin embargo, no aparece incorporado en el Diccionario de la lengua española (DLE).

(7) la gente es como muy yoísta horita [SIC]

(10) si tú no me respetas yo no te voy a respetar, siempre esa ha sido como mi regla
(13) esa es como mi regla pues

(22) estos son como mis dos sueños horita [SIC]

(38) no puedo ser totalmente yo con mi familia, siempre es como que ellos te retraen, o sea, no puedes ser tú mismo

(53) esos cinco meses se nos dificultó todo porque no, como que no encajamos, nuestras maneras de pensar son muy distintas

(54) siempre trato como de encajar con él pero hay algo que lo frena

(56) siempre he tratado como de, a ver, o sea, como de arreglarlo pero es que no puedo

(57) la costumbre es algo... es como una rutina, es como estás acostumbrado a verlo todos los días, hablar con él todos los días

(63) llegó un momento que nos las [SIC] pasábamos muy juntos y empezamos a, como a... o sea como... a compenetrar

(66) él era como un escape, o sea era como el escape que uno a veces necesita de olvidarse de todas esas cosas malas que uno pasa 
(67) él era como un escape, o sea era como el escape que uno a veces necesita de olvidarse de todas esas cosas malas que uno pasa

(71) la verdad que yo... he como visto muchos grupos pues, es como tú eres amigo de fulana, o sea...

(97) me despierto y salgo con mi dolor de cabeza así como hinchada

(105) muchas chicas... al quedar embarazadas... sienten como una presión

(113) he visto que las personas homosexuales tienen muchos problemas consigo mismos, siempre es como una lucha interna

(114) pueden ser buenas personas pero cuando se juntan con otra persona eh... y tienen diferentes maneras de pensar eh... como que chocan mucho

(117) ...tendrían que evaluarlos antes de adoptar un niño (...) yo digo que antes de eso deberían como evaluarlos... psicológica, lo que es mente, la broma

(122) no me gustaría ser alguien como empresario así digo... no sé, siento que eso tiene muchos problemas

Por otra parte, existen 41 casos en los que como actúa introduciendo citas. Sobresaliendo con 36 intervenciones, el esquema como que es el introductor de citas por excelencia. Al decir de B. J. Rivas (comunicación personal, 27 de agosto, 2017), tales casos deberían ser entendidos como aproximativos en el sentido de que aproximan al interlocutor a una experiencia, aparentemente tan privada desde la perspectiva del hablante, que no puede ser referida sino por medio de la cita. Sin embargo, los demás autores revisados (Andersen, 2001; Hasund, 2003; Holmvik, 2011; Jørgensen y Stenström,
2009) le asignan una categoría autónoma a este tipo de usos:

(4) entonces te quedas así como que... hay gente muy cruel y hay gente que le hace falta mucha realidad

(6) hay mucha gente que no le importa pisotearte, es como que... siempre es así, quieren como que bueno, lo bueno para mí, para ti no me importa

(8) eres muy ilusionado, o sea, te... todo es como que jay, si!

(9) eso ya se me está quitando pues, ya es como que, ya, ¡basta!

(12) entonces dices como que te trato mal porque tú tratas mal

cuando no haces lo que te gusta es como que jay no! que... iqué fastidio!, no quiero

cuando estoy en mi casa soy como ah, bueno, sí, soy neutral

no me gusta la gente egocéntrica (...) me quedo así como que ja, ja, ¡cállate, gracias!

cuando eres muy joven y de repente piensas en la muerte piensas como que no, pero es que a mí me quedan muchas cosas por hacer, entonces como que te...

el es un profesor que (...) hace que te adentres en el tema y tú te digas como que ¡berro, quiero saber más!, quiero saber más y más y más y más

(32) la profesora siempre que me veía me trancaba la puerta en la cara (...) y me quedaba así como que ah, $\mathrm{OK}$

siempre es como que... nunca consigo unos amigos que tú digas como que ah, bueno, que duren contigo pues

(39) en vez de apoyarme diciendo que sí puedo me dice eso, entonces me 
quedo así como que ajá, entonces, se supone que eres mi papá

(41) ellos se quedan como que no, te hace falta mucho madurar, que no sé qué cosa, que tienes que crecer, que esto, que lo otro

(42) cuando no tenía teléfono me la pasaba era así como que, papá, ¿me prestas la computadora?

(47) llegó un momento en que después de tanto lo pintas como, o sea, dices como que no, mi papá..., o sea, no odiarlo sino como detestarlo

(49) yo estaba tan nerviosa y tan asustada (...) después caí en cuenta y yo me quedé como que... iay!

(52) yo siempre era como que amor, paz y sabiduría

(61) estoy horita [SIC] como en esa lucha como de ajá, Andrea, [CHAsQUEA LOS DEDOS] iprepárate!

(64) él llegó y dijo como que mira, vamos a intentarlo de nuevo y tal

(69) siempre que yo estoy un grupo social hay la mayoría de personas que les caigo mal (...) siempre es como que jay, ahí viene Andrea!

(70) entonces me quedo así como que ah bueno, me voy, ya, ¿...?, ¡Paola, vámonos!

(72) la verdad que yo... he como visto muchos grupos pues, es como tú eres amigo de fulana, o sea...

(80) si tú estás con una persona que no estudia tú... de repente como que haces la tarea, la broma, y él como que jay!, marico, no hagas eso, vamos a hacer algo

(94) todo lo que tenga que ver con chocolate es como que dame, dame, dame, no, es que no puedes pasar sin darme, si no te mueres
(96) estoy como viendo televisión y como, y a veces como que, papá, te quedó rico el arroz, ah, sí, gracias [REMEDANDO A SU PAPÁ]

(99) hay juventud que está tan dañada, que uno dice como que pero qué pasó con los de antes

(101) es algo triste porque tú te quedas como que cónchale, tengo que luchar porque esto... se levante, porque esto pueda salir adelante

(104) estás de paro siempre, y tú dices como que ¿cuándo me voy a graduar? estoy luchando por graduarme y no... y no puedo

(106) yo lo vi llorar... es como, lo he visto drogado, lo he visto sobrio $\mathrm{y}$ lo he visto llorar

(107) de verdad que me quedo así como que iqué te pasa!, o sea, ¿tú no viste toda la gente que murió ahí solamente por su religión?...

(108) porque es que es como que... ya va, es que $i . . . ?$ y me iba a malandrear burda e' feo

(109) le iba a decir como que bueno, el mío, qué te pasa, o sea, tú eres qué, la única fresa de... la única fresa no, la única Coca-Cola...

(110) Yo sufrí de bullying (...) yo superé eso y dije como que jay, qué tanto, pues!

(111) tú me ves ahí toda fabulosa y todo el mundo ahí como que jay, Andrea!, ¿y eso?, y yo así como que... no

(112) tú me ves ahí toda fabulosa y todo el mundo ahí como que jay Andrea!, ¿y eso?, y yo así como que... no

(118) el poder de teletransportarme, porque, o sea, sería como que ay, me quiero ir a la playa, me voy a la playa, iya! 
(120) ellos ni pendiente con esa señora, o sea, literal es como jay, que se muera!

(121) me afectó mucho pues, porque yo digo como que ¡cómo pudieron dejar morir a esta persona!

(125) me molesta pedir dinero, es como que mamá, me puedes dar para comprarme una...

(126) me siento así como que por qué no trabajo pues

En el listado presentado existe, en primer lugar, un grupo de citas directas, es decir, parlamentos que son o pueden ser dichos por otros $(6,41,64$, $69,80,108,111,120)$; dada la poca probabilidad de realización de varios de ellos. 6, 41, 69, 111 y 120 pueden ser vistos como pensamientos, autoverbalizaciones o, desde un punto de vista más amplio, formas de pensar que la hablante les atribuye a otras personas. En segundo lugar, la lista incluye casos de como antecediendo pensamientos, autoverbalizaciones o formas de pensar, esta vez de la misma hablante $(4,9,12,15,26,29,32,36,47,49,52$, $61,72,99,101,104,106,107,110,112$, 118, 121, 126); varios de ellos, dada su posibilidad real de ser expresados en forma de conducta verbal, pueden entenderse como citas propias, en las que la informante se dirige a otros (12, $32,106,107,112,121)$. En cambio, hay citas que solo pueden formar parte de diálogos (aunque sean hipotéticos) y casi no cabe admitirlas como pensamientos $(8,19,20,39,42,70,94,109$, 125). Aún dentro de este mismo grupo, se encuentran citas en las que hay indicios más o menos claros de una actitud o estado mental de la hablante: estar "ilusionado" (8), desengañarse (9), mostrar igualdad en el trato (12), fastidio o tedio (15), calma (19), rechazo a una actitud $(20,107,109,121,126)$, entusiasmo $(29,118)$, resignación/indiferencia $(32,47,70,110,112)$, sorpresa (49), asunción de un lema (52), anticipación/alerta ante un evento estresante (61), gusto por un alimento (94), duda $(99,104)$ y perseverancia (101). Finaliza la categoría la estructura 96, en la que se aprecia una cita compleja donde la pauta como que sirve para introducir una cita propia, a la vez que para citar la respuesta del interlocutor.

En referencia a la locución conjuntiva, la pauta como que fue así considerada en los tres casos siguientes:

$$
\begin{aligned}
& \text { es como que... tengo una manera } \\
& \text { de entrarle a las personas y que } \\
& \text { las personas puedan confiar en mí } \\
& \text { es como que liberas tensión a } \\
& \text { través de la música } \\
& \text { horita [SIC] no sé, siento que... } \\
& \text { como que mis niveles están ba- } \\
& \text { jos, me siento muy apagada }
\end{aligned}
$$

Desde una perspectiva pragmática, estas locuciones funcionan como operadores que introducen información que el emisor no desea presentar como absoluta, sino en sentido aproximado. Es decir, la información que introducen debe interpretarse como aproximativa, subjetiva, fruto de la apreciación personal del hablante. Ahora, desde un punto de vista formal y en consonancia con los criterios expuestos por Rivas (2016), en las estructuras registradas se hace posible elidir como sin que ello dé lugar a resultados agramaticales; además, es posible sustituir como que + presente del indicativo por como si + imperfecto del subjuntivo. Efectuando ambos arreglos, se obtiene: 
(78) es que... tengo una manera de entrarle a las personas y que las personas puedan confiar en mí

(92) es como si... tuviera/iese una manera de entrarle a las personas y que las personas puedan confiar en mí

es que liberas tensión a través de la música

es como si liberaras/ases tensión a través de la música

(98) horita [SIC] no sé, siento que... que mis niveles están bajos, me siento muy apagada horita [SIC] no sé, siento que... como si mis niveles estuvieran/iesen bajos, me siento muy apagada

Seguidamente, en la tabla 5, se presenta el conteo de los casos de como con valor atenuador, los cuales representan, en su conjunto, el $22 \%$ de la totalidad de los como que exceden el marco de lo puramente sintáctico y casi el $12 \%$ del total de aproximaciones sintáctico-pragmáticas (i.e., incluyendo como que, como si, como para, etc.).

Tabla 5

\section{Registro de frecuencias para los usos atenuadores de la partícula como}

\begin{tabular}{lcccc}
\cline { 2 - 4 } & $\mathbf{f}$ & $\mathbf{\%} \mathbf{A}$ & $\mathbf{\%} \mathbf{B}$ & $\mathbf{\%} \mathbf{~ C}$ \\
\hline Atenuador "típico" & 2 & 13.3 & 2.9 & 1.6 \\
Con matiz atenuador & 9 & 60.0 & 13.2 & 7.1 \\
Atenuador de rasgo positivo & 4 & 26.7 & 5.9 & 3.2 \\
& 15 & 100.0 & 22.0 & 11.9 \\
\hline
\end{tabular}

Nota: $\% \mathrm{~A}=$ porcentaje con respecto al total de usos atenuadores. $\% \mathrm{~B}=$ porcentaje con respecto al total de casos sintáctico-pragmáticos de como (a secas). \% $\mathrm{C}=$ porcentaje con respecto al total de usos sintáctico-pragmáticos.

En principio, están los como que tuvieron un uso atenuador típico, es decir, ellos satisfacen a cabalidad los criterios propuestos por Rivas (2016) a este respecto. En los dos casos que a continuación serán abordados (48, 116), como matiza, minimiza o resta fuerza a un enunciado que por su carga semántica pudiera generar conflictos o desacuerdos con el interlocutor. Así mismo, como funciona a manera de mecanismo de cortesía verbal, mediante el cual la hablante encubre su imagen negativa, al mismo tiempo que refuerza su imagen positiva ante el receptor.

(48) llegó un momento en que después de tanto lo pintas como, o sea, dices como que no, mi papá..., o sea, no odiarlo sino como detestarlo se ponen así como, tiene [SIC] como problemas psicológicos pues 
En la estructura 48, se aprecia que, a través de la partícula como, la joven reduce la fuerza semántica que conlleva la idea de odiar o detestar a su padre, ya que tiene una connotación social negativa. Mientras que en el enunciado 116, la informante desea presentar lo más sutilmente posible la idea de que los homosexuales tienen problemas mentales, por lo que recurre a un mecanismo de atenuación para exponer su opinión.

Ya Rivas (2016) advertía que, en ocasiones, el límite entre el valor aproximativo y el atenuativo de como se hacía borroso. Este es el caso de las siguientes estructuras $(f=9,60 \%)$, las cuales, si bien fueron contabilizadas dentro de los usos aproximativos, no dejan de tener cierto matiz atenuador:

(31) fui buena en matemática y puedo ser una coquito si yo quiero pero nunca me gustó, es como... una maldición

(37) yo tuve como una pelea conmigo misma porque no sabía si decidir estudiar fisioterapia, artes o psicología

(40) Mi mamá es una persona muy cerrada (...) pero... no sé, ya estoy como acostumbrada a eso después de diecisiete años

(45) le empecé como a tener miedo a mi papá

(85) Yo a veces tengo como, ay yo tengo como pánico escénico

(86) sí canto, pero canto como con pena [RIÉNDOSE] (...) no soy como yo misma y no me gusta todavía, por eso digo que tengo como que mejorar eso

(87) sí canto, pero canto como con pena [RIÉNDOSE] (...) no soy como yo misma y no me gusta todavía, por eso digo que tengo como que mejorar eso

(88) sí canto, pero canto como con pena [RIÉNDOSE] (...) no soy como yo misma y no me gusta todavía, por eso digo que tengo como que mejorar eso

...tendrían que evaluarlos antes de adoptar un niño (...) yo digo que antes de eso deberían como evaluarlos... psicológica, lo que es mente, la broma

Con más detalle, se hace malsonante expresarse de las habilidades matemáticas como "una maldición" (31). Tener una "pelea consigo mismo" puede denotar inseguridad personal a la hora de tomar una decisión (37). Seguro no es motivo de orgullo acostumbrarse a tener una madre poco afectuosa (40), ni tampoco lo es admitir tenerle miedo al padre (45). Igualmente, no parece fácil reconocer que se tiene "pánico escénico" (85), 'cantar con pena' (86) o que se debe mejorar en este sentido (88). No 'ser uno mismo' podría involucrar perder algo de la propia originalidad (87). Por último, puede parecer comprometido sostener con firmeza que los homosexuales deban ser evaluados psicológicamente para poder adoptar un niño (117).

Los usos atenuativos restantes $(f=4,27 \%)$ tienen la particularidad de atenuar rasgos positivamente connotados. Aunque dichos usos pueden ser explicados en atención a los mismos principios teóricos de la atenuación de rasgos negativos, Rivas (2016) no halló estructuras de este tipo y, por eso, se ha querido destacar su observación. En las cuatro oraciones que siguen, la informante se presenta de forma positiva y pone en práctica la máxima de modestia, según la cual evita 
definirse directamente como alguien "muy carismática" (11) e intenta presentar a su interlocutor "el don" que ella posee para el trato interpersonal $(75,77)$ y las matemáticas (31) en un sentido aproximado, no estricto.

(11) de verdad que también soy muy como carismática

(31) fui buena en matemática y puedo ser una coquito si yo quiero pero nunca me gustó, es como... un don...

(75) Yo siempre tengo como el don de llevarme bien con cualquier tipo de personas

(77) siempre encuentro como una manera de entrarle a las personas, isiempre!, es alg... jes como un don que tengo!

Cambiando de categoría, en la transcripción solo se halló una estructura en la que como si introduce una comparación hipotética, es decir, producto de una conjetura personal del emisor:

(103) escuchas hablar a las personas y es como si no biesen [sIC] estudiado

Como puede observarse, se introduce información modal acerca de la manera de hablar de un grupo de personas y se forma con el modo subjuntivo. En segundo lugar, la estructura exhibe cierto matiz de ironía, presentando como incultas e ignorantes a las personas a las cuales se hace referencia. El examen del contexto oracional hace suponer que se trata del grupo ideológicamente adverso a la hablante desde el punto de vista político (i.e., quienes apoyan al Gobierno).

Por último, se encontraron 19 casos de como, equitativamente distribuidos entre como y como que, los cuales no se adecuaron a ninguna de las categorías delineadas por Rivas (2016):

(5) hay mucha gente que no le importa pisotearte, es como que... siempre es así, quieren como que bueno, lo bueno para mí, para ti no me importa

para mí Dios es como que, o sea, para mí los seres humanos necesitamos de algo en qué aferrarnos...

cuando eres muy joven y de repente piensas en la muerte piensas como que no, pero es que a mí me quedan muchas cosas por hacer, entonces como que te...

a mí siempre me ha costado mucho hacer amigos no sé por qué, es como que, es como de herencia porque mi mamá también siempre es como que... nunca consigo unos amigos que tú digas como que ah, bueno, que duren contigo pues

él está ahí como, primero porque no consigue donde irse todavía y segundo por mi hermanito porque está chiquito

llegó un momento en que después de tanto lo pintas como, o sea, dices como que no, mi papá..., o sea, no odiarlo sino como detestarlo

él veía las cosas como que... muy [HACE SONAR LOS DEDOS CONTRA LA MESA]... cómo se dice, muy... como a su manera, muy directas, muy malas

siempre he tratado como de, a ver, o sea, como de arreglarlo pero es que no puedo

llegó un momento que nos las [SIC] pasábamos muy juntos $\mathrm{y}$ 
empezamos a, como a... o sea como... a compenetrar

(90) siempre me ha gustado como se... yo siento que tengo como ese lado interior al que quiero ir a todos lados y adentrarme y quedarme en la selva

(115) se ponen así como, tiene [SIC] como problemas psicológicos pues

(119) tengo miedo a estar sola, o sea, es como que, no sé, no me gusta sentirme sola

De manera preliminar, tales usos fueron denominados vacilantes, ya que con excepción de la oración 27 , la cual parece tratarse de una verdadera intervención trunca, lo que distingue a estas estructuras es el papel que juega como en la búsqueda de concreción por parte de la hablante, unas veces con respecto a una idea $(5,23,35,44,46,68,81,82$, $90,113)$ y otras con respecto a un término $(33,50,55,62,74,84,115)$. Tan es así que en varios casos como desembocó en un uso aproximativo, denotando imprecisión en la expresión $(33,50,55,62$, $84,90)$ o fungiendo como marcador de cita $(5,35,46)$. Asimismo, casi todos los enunciados están cargados de diversos elementos contextuales que permiten el tratamiento de como en calidad de correlato del proceso cognitivo de adecuación emprendido por la hablante.

Desde el punto de vista semántico, resulta de interés destacar que hubo casos en los que el referente del parlamento proferido por la informante gozaba de un alto nivel de abstracción: Dios (23), la muerte (27), las cosas (50) y los problemas psicológicos (115); en otros, el enunciado incorporaba una idea con algún matiz retórico: "pisotearte" = humillarte (5), "me quedan muchas cosas por hacer" = queda mucho tiempo de vida (27), "hacer amigos" = establecer relaciones de amistad (33), "lo pintas"= te formas una idea acerca de alguien (46), "veía las cosas" = evaluaba las situaciones (50), "te dejas llevar" = te convencen $(81,82)$ y "lado interior" = rasgo de personalidad poco exteriorizado (90).

Se advierten estructuras sintácticas problemáticas o mejorables. Tal como se deduce de lo afirmado por Barrera (1991) y Parra (2004), estas construcciones aumentan su probabilidad de ocurrencia en el marco de un discurso oral cuya producción es simultánea con su planificación y organización: "uno dice no, no... utilizarlo porque sino ina-da!" en vez de "uno dice no, no... hay que utilizarlo porque sino ¡na-da!” (68), “mi grupo social (...) van a ser como que..." en lugar de "mi grupo social (...) va a ser/sería como que..." (74), "tengo como ese lado interior al que quiero ir a todos lados" en vez de "tengo como ese lado interior con el que quiero ir a todos lados" (90) y "se ponen así como, tiene [SIC] como problemas psicológicos pues" en vez de "se ponen así como, tienen como problemas psicológicos pues” (115).

A nivel lexical, el marcador de inconcreción "pues" manifiesta una manera poco precisa de expresarse. 
De igual forma, destacan expresiones dubitativas/explicativas: "o sea" (23, $46,55,62,119)$, "no sé" $(33,119)$, "cómo se dice" (50), "a ver" (55) y "ay" (84); incluso, se acude a la repetición léxica: "o sea" (46), "muy" (50) y "no" (68).

Las pausas transitorias también reclaman su función en la planificación del discurso (nótense los puntos suspensivos en 5, 35, 46, 50, 62, 68, 74, $81,82)$. Finalmente, en el ámbito de lo gestual, hacer sonar los dedos contra la mesa durante la pronunciación del enunciado 50 es una pista contextual que puede sumarse a la idea de que la hablante se encontraba buscando la palabra adecuada para expresarse.

\section{Discusión}

El objetivo de este estudio fue describir los usos sintáctico-pragmáticos de la partícula como en el lenguaje oral de una usuaria de la variedad caraqueña del español venezolano. La aproximación emprendida logró percibir la multifuncionalidad de la referida partícula, es decir, el hecho de que puede participar en diversas construcciones, cumpliendo diferentes funciones desde el punto de vista sintáctico, así como también dar lugar a estructuras cuya interpretación obedece a razonamientos de carácter semántico, pragmático y discursivo.

A diferencia de Rivas (2016), quien observó un predominio de las estructuras cuyo análisis obedece a criterios estrictamente sintácticos, en este trabajo los usos de como que ameritan una interpretación sintáctica y pragmática fueron la contundente mayoría. Esto pudiera explicarse en atención al tipo de lenguaje analizado en uno y otro estudio: la oralidad es terreno altamente propicio para el uso de diversos marcadores interaccionales, cuya presencia es prácticamente nula en la escritura (Barrera, 1991), más aún si se piensa en textos con importantes niveles de formalidad (como el tradicional artículo de opinión). Además, el discurso hablado alcanza un mayor grado de redundancia y la información transmitida puede ser complementada por una serie de recursos suprasegmentales y extralingüísticos, aspectos que llegan incluso a determinar su eficacia comunicativa (Barrera, 1991; Parra, 2004). En efecto, se documentó que, en varios casos, como se hizo acompañar de repeticiones, vacilaciones, gestos, pausas... elementos que no tienen cabida en el texto escrito. Por otro lado, aunque los usos formales de como representaron la mayoría de los totalizados en el corpus de Rivas (2016), los datos obtenidos por esta autora habían mostrado cierto crecimiento en cuanto a cantidad y variedad de usos pragmáticos o discursivos en la actualidad, lo que, en primer lugar, evidencia la riqueza de la partícula como y, en segundo lugar, sugiere que estos usos pragmáticos e innovadores parecieran estar cobrando cada vez mayor vigencia entre los usuarios y se encuentran en franco proceso de expansión.

El uso estrictamente aproximativo de como se da cuando este modifica una expresión numérica o una cantidad (Jucker y Ziv, 1998; Pavón, 1999; Said-Mohand, 2008). Matte Bon (1992) se refiere a este uso aproximativo, indicando que se emplea cuando se quiere presentar una cantidad como una valoración subjetiva de quien habla. Asimismo, explica que el uso aproximativo de la partícula como se registra cuando el hablante quiere poner un suceso en 
relación con una fecha $\mathrm{u}$ hora aproximada. Rivas (2016) sentencia que en estas estructuras se manifiesta incertidumbre en cuanto a la cantidad a la cual se hace referencia.

Además de los usos aproximativos que se refieren de manera exclusiva a cantidades, se distinguen aquellos en los que el hablante tiene dudas sobre la veracidad de su enunciado (RAE, 2010; RAE/ASALE, 2005; Rivas, 2016). Entre estos se cuentan los usos aproximativos de modo reportados por Martínez (1954) y los descritos por Cuervo (1998). Este último autor mencionó algunas estructuras que se emplean cuando el emisor no conoce el nombre el objeto al cual hace referencia o tiene dudas al respecto. Solo recientemente se ha entendido a plenitud el uso de la partícula como en sentido aproximativo, esto es, cuando a través de ella, el hablante presenta una proposición de manera insegura, resultado de una apreciación personal, tratándose, en todo caso, de construcciones que no deben interpretarse de manera estricta sino aproximada (Rivas, 2016). Con todo, las palabras de Jørgensen (2012) parecen las más abarcadoras: el marcador como adquiere la función de aproximador cuando relativiza la expresión que lo sigue, modificando su significado. Este es el tipo de estructuras que el presente estudio reconoció.

Varios autores (Channell, 1994; Fuentes, 2008; Jørgensen, 2012; Jucker, Smith y Lüdge, 2003; Stenström, 2009) denominan a la aproximación no numérica como enunciativa o vaga, porque cede al oyente el papel de la interpretación, por lo que puede ser entendida como una estrategia de cortesía. Ahora bien, el lenguaje vago o poco preciso es frecuente en el lenguaje juvenil por varios motivos. A menudo, los jóvenes pueden tomar parte en ambientes restringidos, con un marco de referencia común, en los cuales no necesitan dar muchas explicaciones. Otra razón parece ser una cierta resistencia cognitiva a la exactitud lingüística. Parece también que hablar con vaguedad es un objetivo en sí mismo que tiene una función social, pues genera una sensación de compañerismo y de pertenencia al grupo (Fuentes, 2008; Jucker et al., 2003).

En un número importante de casos, como fue usado como introductor de cita. Las investigaciones antecedentes foráneas han conseguido que, efectivamente, como (al igual que el inglés like y el noruego bare y liksom) puede ser empleado para introducir citas de habla directa, pensamientos propios o ajenos, sonidos no lexicológicos, gestos o expresiones faciales, e incluso puede referir una actitud o estado mental más general (Andersen, 2001; Hasund, 2003; Holmvik, 2011; Jørgensen y Stenström, 2009; Romaine y Lange, 1991).

El análisis de la función de introductor de estilo directo permite afirmar que en muchos casos la cita no es literal, sino solo una aproximación a lo que se ha dicho (Andersen, 2001; Hasund, 2003; Holmvik, 2011; Jørgensen, 2012; Jørgensen y Stenström, 2009; Schourup, 1985). Por ejemplo, está claro que lo que se introduce con el como de citación en los casos 6, 69 y 120 no es una cita palabra por palabra de lo que otros han dicho, sino lo que a la joven entrevistada le parece que piensan/dicen los individuos egoístas ("bueno, lo bueno para mí, para ti no me importa"), las personas ante su llegada (“'iay, ahí viene Andrea!') y los familiares de una anciana (“iay, que se muera!”). Lo mismo sucede cuando la cita es propia; 
en este sentido, destacan por su capacidad ilustrativa los casos 20 y 94 . En el primero se percibe que la cita introducida por el marcador como no es literal (“ja, ja, icállate, gracias!”) y en el segundo la solicitud de chocolate hecha por la hablante exige una interpretación en sentido figurado ("dame, dame, dame, no, es que no puedes pasar sin darme, si no te mueres").

Aprovechando la pertinencia del ejemplo anterior cabe agregar que, según Meehan (1991), las citaciones con como elevan el efecto dramático de la narración. De hecho, esta es la razón por la que Holmvik (2011) opina que como puede desempeñar tanto el papel de marcador de cita como el de intensificador. De acuerdo con De Ledezma y Obregón (1991), la utilización de recursos dramáticos es típica en el relato experiencial del adolescente venezolano, lo cual incluye la "traducción" de ciertas acciones o hechos al estilo directo para atraer y mantener la atención del interlocutor. Son precisamente las adolescentes provenientes de ambientes urbanos las que producen la mayoría de las citas directas con como (Ferrara y Bell, 1995; Hasund, 2003). Aunque a primera vista la presencia de este marcador se asocie solo con el lenguaje oral (de allí que Rivas [2016] no lo registrara), se le ha podido observar inmerso en el lenguaje utilizado en las redes sociales (i.e., la ciberlengua), de modo que un factor que parece ser determinante en su empleo es el hecho de encontrarse en un contexto que admita un tipo de registro coloquial, un habla más familiar y corriente.

En el apartado previo, se pudo evidenciar el uso atenuador de la partícula como. Para Briz (2001, 2003), la atenuación es una estrategia discursiva derivada de la actividad argumentativa mediante la cual se intenta ganar la colaboración y el acuerdo de parte del receptor. Con este propósito, el emisor se presenta como un individuo amable, modesto y colaborativo. El empleo de la partícula como es, en efecto, uno de los recursos lingüísticos a través de los cuales se consigue la atenuación, esto es, mitigar o restarle importancia al contenido de una proposición (Marcano, 2007a, 2007b; Montes, 1980-1981; Okihara, 1998). Según Briz (2001), la atenuación debe entenderse como un rodeo expresivo y estratégico, es decir, como un intento del hablante de presentar su punto de vista pero de forma indirecta, como algo relativo, producto de un juicio o apreciación personal. Asimismo, la atenuación como estrategia conversacional puede explicarse desde algunos de los postulados de la teoría de la cortesía, entre los cuales se destacan la máxima de modestia (i.e., sea modesto) y la de generosidad (i.e., sea generoso, haga que su interlocutor se sienta cómodo). Atendiendo a estos planteamientos, explica Briz (2001) que la atenuación responde no solo a los fines de aminorar las cualidades y apreciaciones negativas propias, sino también las que están barnizadas con un matiz positivo, en ambos casos guiados por el ánimo de no imponerse o, cuando menos, de que tal objetivo no sea evidente.

Además de ser un mecanismo que promueve la cortesía y reduce los desacuerdos entre los participantes, la atenuación es también una estrategia argumentativa que se emplea para ganar en el "juego comunicativo" (Fuentes y Alcaide, 2002). En este sentido, según lo plantean estos autores, atenuar el contenido de un enunciado 
puede obedecer a los siguientes propósitos: acercarse a un oyente y convencerle, evitar que lo dicho pueda afectar negativamente la imagen del interlocutor o que no sea aceptado por este, así como presentarse de manera positiva y no como alguien que se impone o habla de manera tajante. Pues bien, con esos fines, la lengua cuenta con una serie de herramientas, técnicamente conocidas con el nombre de operadores argumentativos, que permiten matizar lo dicho y no presentarlo como una imposición, sino como una idea discutible, resultado de una apreciación personal. Desde esta óptica, la partícula como sería lo que Fuentes y Alcaide (2002) llaman un modificador desrealizante, una partícula que aminora el contenido semántico de la unidad a la que modifica (casi siempre un adjetivo, al cual se le resta fuerza argumentativa colocándolo en una escala inferior).

Tomando en cuenta que la atenuación puede explicarse también desde la teoría de la argumentación, las aproximaciones hasta este punto expuestas tienen en común el hecho de enfatizar en que, si bien la atenuación se trata de una herramienta que permite alcanzar los objetivos comunicativos, es un mecanismo de cortesía del que se vale el enunciador para proteger su imagen o, como sugiere Briz (2004), un instrumento con el que se busca el equilibrio entre los participantes del acto comunicativo. Se estaría entonces en presencia de un tipo de cortesía estratégica mediante la cual el hablante se distancia o aleja de su mensaje con el propósito de acercarse a su interlocutor (Briz, 2007; Jucker y Ziv, 1998).

Briz (2004) también apunta que la atenuación es un medio con el que se minimiza lo enunciado, con el fin de librarse de los efectos que pudiera causar el mensaje. Se trata de una operación que afecta el valor intencional de lo dicho, al tiempo que es una estrategia argumentativa de negociación, promotora del acuerdo, reguladora de las relaciones interpersonales. Los atenuantes son manifestaciones verbales de cortesía, es decir, marcadores lingüísticos de la intención y, como se ha insistido, mitigan, suavizan la fuerza ilocutiva o la carga significativa de una expresión con el propósito de salvar la imagen (Hernández, 2004). Lo importante es entender que este tipo de marcadores están convencionalizados y que no pueden comprenderse fuera de contexto, de allí que el matiz abiertamente subjetivo sea innegable y se precise de principios pragmáticos al momento de interpretarlos.

En resumen, lo expuesto en este apartado permite afirmar que el uso de la partícula como en calidad de atenuante es: (a) un recurso lingüístico de argumentación que le permite al emisor matizar, minimizar, desrealizar y, en definitiva, rebajar la fuerza argumentativa de un elemento del enunciado con el fin de alcanzar su propósito comunicativo, el cual pudiera estar referido a plantear de manera cortés una proposición, evadiendo así posibles desacuerdos o conflictos en la interacción con su receptor; y (b) un mecanismo de cortesía verbal que le permite al enunciador encubrir sus rasgos negativamente valorados ante su interlocutor y, a la vez, realzar la imagen positiva propia, entendiendo por ella la aceptación social que se intenta promover con cada acto comunicativo.

En referencia a las vacilaciones identificadas, hay que decir que -en consonancia con los comentarios 
hechos en la sección de hallazgosotras investigaciones (e.j., Andersen, 2001; Coates, 1996; Hasund, 2003; Jørgensen y Stenström, 2009) han sugerido que como colabora en la búsqueda de las palabras más adecuadas cuando es usado en relación con pausas, reformulaciones, explicaciones y reparaciones. Además de reafirmar esta aseveración, Holmvik (2011) se da a la tarea de hallar toda clase de indicadores de que, en esos casos, el hablante está buscando la palabra o manera más idónea para explicar lo que desea. Como en este trabajo, el autor consigue que la repetición de palabras sea un elemento por considerar. Siendo así, aun cuando como pareciera ser usado sin ningún fin aparente, puede comportarse como un elemento léxico que ayuda a "ir al grano" o le proporciona al hablante más tiempo mientras da con las palabras acertadas. Jørgensen (2008) ha ido más allá y ha planteado que la elevada frecuencia de uso entre los jóvenes de los marcadores discursivos tipo como guarda relación con la inseguridad que, en general, caracteriza a quienes atraviesan la etapa entre la niñez y la madurez.

En general, se sabe que el uso del marcador pragmático like (cuyo equivalente en español es como) es más frecuente entre los jóvenes ingleses (Jørgensen y Stenström, 2009). Asimismo, de acuerdo con Matte Bon (1992), el uso aproximativo de la partícula como es más usual en el lenguaje juvenil, sobre todo en los casos donde el hablante desea poner un suceso en relación con una fecha aproximada. En cuanto a las clases sociales, parece que el uso de like/como con una función pragmática se hace más frecuente conforme se asciende en el nivel socioeconómico (Andersen, 2001;
Holmvik, 2011; Jørgensen, 2012; Marcano, 2007a). Por su parte, las chicas usan el como con función de marcador pragmático con mayor frecuencia que los chicos (Hasund, 2003; Jørgensen y Stenström, 2009; Marcano, 2007a), haciéndose notar en la función de cita la distinción más clara entre los sexos (Holmvik, 2011). Los mencionados son factores extralingüísticos que, de una u otra forma, ayudan a explicar la profusión en el empleo de como observado en la presente investigación.

Aparte de la frecuencia de uso de la partícula, llama la atención que de las 19 categorías delimitadas por Rivas (2016), la hablante haya circunscrito su expresión a cinco de ellas, todas en mayor o menor medida signadas por la aproximación, ya sea en su forma clásica o como parte de la imprecisión misma que entraña la atenuación, la locución conjuntiva, la comparación hipotética y la vacilación. De manera que resulta obligante preguntarse si el uso de como, en los términos expuestos, podría ser un indicador de "pobreza discursiva". En el plano cognitivo de la interacción lingüística, Haverkate (1994) sostiene que al uso de los atenuantes, entre ellos del como atenuativo descrito en este artículo, "subyace el fenómeno de que al hombre, como usuario de lengua, le falta capacidad de definir con exactitud las categorías empíricas mediante las cuales organiza la realidad de su vida cotidiana" (p. 211). Para Jørgensen y Stenström (2009), hasta cierto punto se puede decir que el uso de como es consecuencia de un "mal hábito". No obstante, reconocen que se trata de un marcador muy práctico para los hablantes, ya que trabaja tanto en el nivel discursivo estratégico, como organizador de turno y 
herramienta de planificación, como a nivel interaccional, manteniendo el contacto con el oyente y comprometiéndole más. De todos modos, considerando que los miembros de los niveles más altos de la escala social tienen mayores oportunidades de estudio y habida cuenta de que precisamente es la clase alta la que concentra la mayoría de los casos del uso de como con función de marcador pragmático, no pareciera entonces que la recurrencia a este tipo de estructuras guardara relación con un bajo nivel educativo por parte de los hablantes. Por último, al igual que Marcano (2007a), B. J. Rivas (comunicación personal, 30 de octubre, 2017) afirma que como constituye un recurso productivo en la interacción verbal cotidiana y que, por tanto, su empleo no es cercenable.

Como es natural, este trabajo presenta algunas limitaciones. Desde el punto de vista teórico, ya Rivas (2016) advertía que la bibliografía disponible sobre el tema, aunque relativamente abundante, ofrecía interpretaciones muy diversas y hasta polémicas con respecto a los usos de como. Sin rodeos debe decirse que, pese a las indudables fortalezas que se tuvo a bien destacar, la taxonomía elaborada por Rivas (2016) deja de captar varias de las singularidades que la mencionada partícula exhibe en la modalidad oral del lenguaje. Después de todo, no se puede pasar por alto que, si bien la autora centró su análisis en la variedad del español de Venezuela, lo hizo utilizando como insumo artículos periodísticos de opinión, cuyos autores se mueven entre las así llamadas variedades culta y estándar de la lengua, hecho que desde luego contrasta con la elección de una hablante que se expresó espontáneamente en un contexto que intentó representar su cotidianidad.

Justamente, ahora desde un punto de vista metodológico, es de resaltar que, por tratarse de un estudio de caso único, los resultados no se pueden generalizar. Por otra parte, la información que sobre la participante se maneja puede presentar el sesgo propio del autoinforme. Además, su clase social fue determinada con un método al que ya se le ha acusado de no reflejar la realidad de la condición social de las familias venezolanas. Otra limitación, esta vez inherente a un diseño de investigación sincrónico, es la necesidad de tratar con mayor profundidad el asunto del cambio lingüístico, ya que, siendo los jóvenes importantes propulsores de este, interesa conocer si la prevalencia identificada en este estudio se podría mantener en el tiempo.

Por lo pronto, próximos estudios deberían trabajar con una muestra de mayor tamaño que asegure su representatividad, así como prestarle atención a las variables sociolingüísticas que típicamente afectan los datos obtenidos, por ejemplo, examinando si hay diferencias en el perfil descrito según el sexo y la clase social de los informantes. Solamente en este punto tendría sentido la generación de una taxonomía que considere la variedad de usos de la palabra como en el español hablado de Venezuela. El presente ha sido un trabajo que apenas exploró esa posibilidad. 


\section{Bibliografía}

Andersen, G. (2001). Pragmatic markers and sociolinguistic variation: $A$ relevance-theoretic approach to the language of adolescents. Amsterdam: John Benjamins.

Barrera, L. (1991). Del sonido a la grafía: texto oral y texto escrito. En A. Puente (Ed.), Comprensión de la lectura y acción docente (pp. 184205). Madrid: Fundación Germán Sánchez Ruipérez.

Bernárdez, E. (1999). ¿Qué son las lenguas? Madrid: Alianza.

Blas, J. (2005). Sociolingüística del español. Desarrollos y perspectivas en el estudio de la lengua española en contexto social. Madrid: Cátedra. (2001). El español coloquial en la conversación. Esbozo de pragmagramática. (2. ${ }^{\mathrm{a}}$ ed.). Barcelona: Ariel.

(2003). La interacción entre jóvenes. Español coloquial, argot y lenguaje juvenil. En M. Echenique y J. Sánchez (Eds.), Lexicografía y lexicología en Europa y América. Homenaje a Homenaje a Günther Haensch en su 80 aniversario (pp. 141-154). Madrid: Gredos. (2004). Cortesía verbal codificada y cortesía verbal interpretada. En D. Bravo y A. Briz (Eds.), Pragmática sociocultural. Estudios sobre el discurso de cortesía en español (pp. 67-93). Barcelona: Ariel.

(2007). Para un análisis semántico, pragmático y sociopragmático de la cortesía atenuadora en España y América. LEA: Lingüistica Española Actual, 29(1), 5-40.

Channell, J. (1994). Vague language. Oxford: Oxford University Press.
Coates, J. (1996). Women talk: Conversation between women friends. Oxford: Blackwell.

Cuervo, R. (1998). Diccionario de construcción y régimen de la lengua castellana (Tomo II. Letras C-D). Barcelona: Herder.

De Ledezma, M. y Obregón, H. (1991). El relato experiencial en el adolescente venezolano. Letras, 48, 101108. Recuperado de http://revistas. upel.edu.ve/index.php/letras/article/view/5972

Escandell, M. (1996). Introducción a la pragmática. Barcelona: Ariel.

Ferrara, K. y Bell, B. (1995). Sociolinguistic variation and discourse function of constructed dialogue introducers: The case of be + like. American Speech, 70(3), 265-290. doi: $10.2307 / 455900$

Flores, L. (1991). La pre-investigación sociolingüistica: una propuesta a través del presente histórico (Trabajo de ascenso). Universidad Pedagógica Experimental Libertador, Instituto Pedagógico de Caracas, Venezuela.

Fuentes, C. (2008). La aproximación enunciativa. LEA: Lingüistica Española Actual, 30(2), 223-258.

Fuentes, C. y Alcaide, E. (2002). Mecanismos lingüísticos de la persuasión: cómo convencer con palabras. Madrid: Arco Libros.

Hasund, I. (2003). The discourse markers like in English and liksom in Norwegian teenage language: a corpus-based, cross-linguistic study (Tesis doctoral inédita). Universitetet i Bergen, Noruega.

Haverkate, H. (1994). La cortesía verbal. Estudio pragmalingüístico. Madrid: Gredos. 
Hernández, N. (2004). La cortesía como búsqueda del equilibrio de la imagen social. En D. Bravo y A. Briz (Eds.), Pragmática sociocultural. Estudios sobre el discurso de cortesía en espanol (pp. 95-108). Barcelona: Ariel.

Hernández, R., Fernández, C. y Baptista, P. (2014). Metodología de la investigación. ( $6^{\mathrm{a}}$ ed.). México: McGraw-Hill Interamericana.

Herrero, G. (2002). Aspectos sintácticos del lenguaje juvenil. En F. Rodríguez (Ed.), El lenguaje de los jóvenes (pp. 67-96). Barcelona: Ariel.

Holmvik, L. (2011). Como usado como marcador del discurso en el lenguaje juvenil de Madrid (Tesis de maestría, Universitetet i Bergen, Noruega). Recuperada de http://dspace.uib.no/handle/1956/7357

Jørgensen, A. (2008). Tío y tía como marcadores en el lenguaje juvenil de Madrid. En I. Olza, M. Casado y R. González (Eds.), Actas del XXXVII Simposio Internacional de la Sociedad Española de Lingüística (pp. 387-396). Pamplona: Universidad de Navarra.

Jørgensen, A. (2012). Funciones del marcador pragmático como en el lenguaje juvenil español y chileno. En M. Placencia y C. García (Eds.), Pragmática y comunicación intercultural en el mundo hispanohablante (pp. 209-231). Amsterdam: Rodopi.

Jørgensen, A. y Martínez, J. (agosto, 2007). Los marcadores del discurso del lenguaje juvenil de Madrid. Revista Virtual de Estudos da Linguagem, 9(5). Recuperado de http://bora.uib.no/handle/1956/12523

Jørgensen, A. y Stenström, A. (2009). Dos marcadores pragmáticos contrastados en el lenguaje juvenil: el inglés like y el español como. Español Actual, 92, 103-121.

Jucker, A. y Ziv, Y. (1998). Discourse markers: Descriptions and theory. Amsterdam: John Benjamins.

Jucker, A., Smith, S. y Lüdge, T. (2003). Interactive aspects of vagueness in conversation. Journal of Pragmatics, 35(12), 1737-1769. doi: 10.1016/S0378-2166(02)00188-1

Lázaro, F. (1980). Estudios de lingüística. Barcelona: Crítica.

Marcano, Z. (2007a). "En Caracas la gente es como más vacía": una aproximación al uso del como atenuativo en el habla de Caracas, Maracaibo y Mérida (Venezuela). Akademos, 9(1), 3959. Recuperado de http://saber.ucv.ve/ ojs/index.php/rev_ak/article/view/672

Marcano, Z. (2007b). "Y la niñita fue un poquito tonta": adquisición de algunas estrategias de atenuación en un corpus de habla caraqueño. Núcleo, 19(24), 97-112. Recuperado de http://www.scielo.org.ve/pdf/nu/ v19n24/art04.pdf

Márquez, E. (2007). La entrevista cualitativa. Ensayo y Error, 16(33), 127-144. Recuperado de http://earevistas.unesr.edu.ve/index.php/ eye/article/view/83

Martínez, E. (1954). Diccionario gramatical. Barcelona: Ramón Sopena.

Matte Bon, F. (1992). Gramática comunicativa del español. Madrid: Edelsa.

Meehan, T. (1991). It's like, 'What's happening in the evolution of like?: A theory of grammaticalization. Kansas Working Papers in Linguistics, 16, 37-51. doi: 10.17161/ KWPL.1808.423

Méndez Castellano, H. y Méndez, M. C. (1994). Sociedad y estratificación. Método Graffar-Méndez Castellano. Caracas: Fundacredesa. 
Montes, J. (1980-1981). Sobre el como de atenuación. Boletín de Filología de la Universidad de Chile, 31(2), 667-677. Recuperado de http:// www.boletinfilologia.uchile.cl/index.php/BDF/article/view/46598

Navdal, T. (2007). Las palabras tabú del lenguaje juvenil madrileño (Tesis de maestría, Universitetet i Bergen, Noruega). Recuperada de http:// bora.uib.no/handle/1956/2612

Okihara, M. (1998). Consideración sobre el como atenuativo. Lingüística Hispánica, 21, 1-19.

Parra, M. (2004). Cómo se produce el texto escrito. Teoría y práctica. (3. ${ }^{\mathrm{a}}$ ed.). Bogotá: Magisterio.

Pavón, M. (1999). Clases de partículas: preposición, conjunción y adverbio. En I. Bosque y V. Demonte (Eds.), Gramática descriptiva de la lengua española (Vol. 1, pp. 565-657). Madrid: Espasa Calpe.

Real Academia Española (2010). Nueva gramática de la lengua española. Manual. Barcelona: Espasa Libros.

Real Academia Española / Asociación de Academias de la Lengua Española (2005). Diccionario panhispánico de dudas. Bogotá: Santillana.

Rivas, B. (2016). El que mucho habla es como la mula que mucho anda, que al final tropieza. Un estudio de los usos de como en artículos de opinión venezolanos de los siglos XIX y XXI (Tesis de maestría inédita). Universidad Pedagógica Experimental Libertador, Instituto Pedagógico de Caracas, Venezuela.

Rodríguez, F. (2002). El lenguaje de los jóvenes. Barcelona: Ariel.

Romaine, S. y Lange, D. (1991). The use of like as a marker of reported speech and thought: A case of grammaticalization in progress.
American Speech, 66(3), 227-279. doi: $10.2307 / 455799$

Said-Mohand, A. (2008). Aproximación sociolingüística al uso del marcador del discurso como en el habla de jóvenes bilingües en la Florida. Revista Internacional de Lingüistica Iberoamericana, 6(2), 71-93.

Schourup, L. (1985). Common discourse particles in English conversation. Nueva York: Garland.

Stenström, A. (2009). Vague category markers in London and Madrid youthspeak. En R. Bowen, M. Mobärg y S. Ohlander (Eds.), Corpora and Discourse - and Stuff. Papers in Honour of Karin Aijmer (pp. 287-295). Gotemburgo: University of Gothenburg.

Villegas, C. (2011). Conocer la enunciación y convencer con palabras: introducción a la pragmagramática (Trabajo de ascenso). Universidad Pedagógica Experimental Libertador, Instituto Pedagógico de Caracas, Venezuela.

Yao, J. (2008). Pluralidad funcional de como en la obra teatral Bajarse al moro para la enseñanza de ELE. marcoELE, 7, 1-9. Recuperado de http://marcoele.com/descargas/7/ jumming_yao.pdf

Zabalegui, N. (2015). Una tarde encontré un disco así grande de aquella época: los usos de así en el español hablado de Caracas. Boletín de Lingüistica, 27(43-44), 91-117. Recuperado de http://saber.ucv.ve/ojs/index.php/rev_bl/article/view/11856

Zimmermann, K. (2002). La variedad juvenil y la interacción verbal entre jóvenes. En F. Rodríguez (Ed.), El lenguaje de los jóvenes (pp. 137164). Barcelona: Ariel. 


\section{Anexo}

\section{Estructuras de interpretación sintáctico-pragmática: criterios para la clasificación de como (Rivas, 2016)}

\section{Criterios para analizar como}

Criterios para considerar como en calidad de ejemplificativo

1) El segmento al que preceden constituye una ilustración de una afirmación hecha en un enunciado previo.

2) Como se conmuta por frases como por ejemplo, entre las que se cuentan y otras semejantes.

3) Los elementos introducidos por como van pospuestos al segmento al que sirven de ilustración.

4) El uso ejemplificativo de como admite la incorporación del cuantificador tan siempre que pueda parafrasearse por estructuras encabezadas por frases como por ejemplo y otras semejantes.

Criterios para considerar como en calidad de locución conjuntiva exceptiva

1) Siempre que a nivel semántico introduzca información hipotética que se considera excepcional.

2) como no sea que es locución conjuntiva exceptiva cuando se sustituye por la pauta a menos que.

Criterios para considerar la pauta verbo subjuntivo + como + verbo subjuntivo en calidad de marcador de indiferencia

- El emisor desea manifestar su indiferencia con respecto a un planteamiento.

- Suelen formarse de la siguiente forma: subjuntivo + como + subjuntivo.

- La secuencia subjuntivo + como + subjuntivo, es conmutable por sea como sea.

Criterios para considerar como en calidad de introductor de negación enfática

- Se ponen en relación cosas o circunstancias.

- El enunciador niega categóricamente un enunciado o parte del mismo. 
Criterios para considerar como en calidad de introductor de enunciados aproximativos

1) Cuando el hablante desea presentar su enunciado como hipotético, una idea producto de una percepción personal que no necesariamente debe ajustarse a la realidad y mucho menos ser compartida por el otro.

2) El hablante desea alejarse de su proposición, fundamentalmente porque no tiene la información suficiente para comprometerse con la veracidad del enunciado. Esto sucede fundamentalmente cuando el hablante no tiene conocimiento sobre el nombre exacto del objeto al cual hace referencia.

3) De la misma manera consideraremos aproximativas aquellas estructuras en las que se manifiesta incertidumbre en cuanto a la cantidad a la cual se hace referencia. 4) Asimismo, incluiremos entre los usos aproximativos aquellas estructuras en las que el hablante introduce incertidumbre en cuanto a una fecha $u$ hora.

5) Finalmente, asimilaremos al paradigma de los aproximativos aquellas pautas formadas con como con las que el hablante expresa vacilación o imprecisión en la expresión empleada.

Criterios para considerar como en calidad de atenuador

1) Cuando como matiza, minimiza o resta fuerza a un enunciado que por su carga semántica pudiera generar conflictos o desacuerdos con el interlocutor.

2) En estos casos como es un mecanismo de cortesía verbal, mediante el cual el hablante protege su imagen negativa, a la vez que refuerza la imagen positiva de su receptor.

\section{Criterios para analizar la pauta como que}

Criterios para considerar la pauta como que en calidad de locución conjuntiva

1) Como que se considera locución conjuntiva siempre que desde un punto de vista formal pueda sustituirse por como si. En estos casos como que se presenta con indicativo, y como si con subjuntivo.

2) Pueden presentarse estructuras a partir de la pauta como que si.

3) Desde un punto de vista pragmático la información que introduce esta locución debe interpretarse como aproximativa, subjetiva, fruto de la apreciación personal del hablante.

4) Como que será considerada locución conjuntiva siempre que sea posible la elisión de como sin dar lugar a resultados agramaticales.

Criterios para considerar como que en calidad de introductor aproximativo

- Como que con matiz aproximativo pero no conmutable por como si + subjuntivo.

- No es posible la elisión de como sin que dé lugar a resultados agramaticales. 
Criterios para considerar la pauta como que en el paradigma de los usos ejemplificativos

- Introducen elementos que ilustran una idea planteada en un enunciado previo.

- Como que no puede anteponerse al segmento por él introducido.

- Puede conmutarse por otra estructura que introduce ejemplos.

Criterios para considerar la pauta como que en calidad de conjunción continuativa

1) Consideraremos que como que es conjunción continuativa siempre que sea sustituible por así que o tan cierto es esto que.

Criterios para considerar la pauta como que en calidad de locución conjuntiva causal

1) Como que será considerada locución conjuntiva causal siempre que a nivel semántico introduzca elementos que expliquen o justifiquen el contenido subyacente en el enunciado previo.

2) Siempre que pueda sustituirse por la conjunción porque.

\section{Criterios para analizar la pauta como si}

Criterios para considerar la pauta como si en calidad de locución conjuntiva

Véanse los criterios para considerar la pauta como que en calidad de locución conjuntiva.

Criterios para considerar la pauta como si en calidad de introductor de comparación hipotética

- Se forma con verbos en subjuntivo y aporta información modal de la oración principal.

- Hace referencia a una comparación hipotética o tiene matiz de ironía.

- Suelen posponerse a la oración principal.

Criterios para considerar la pauta como si en calidad de introductor negativo fuerte

- Introduce un enunciado mediante el cual se desaprueba una proposición.

- Va pospuesta a la oración principal.

- Ocupa la posición inicial cuando se quiere tematizar la desaprobación de un planteamiento. 


\section{Criterios para analizar la pauta como para}

Criterios para considerar la pauta como para en calidad de introductor de enunciados aproximativos

- Siempre que se introduzca una conjetura subjetiva que se presenta como insegura o incierta, en este sentido puede tratarse de una evaluación positiva o negativa.

Criterios para considerar la pauta como para en calidad de marcador de intensidad consecutiva

- Introduce la idea de negación, imposibilidad o duda.

- Aparece en relación con los cuantificadores bastante, suficiente u otros.

- El uso de la partícula como es potestativo y puede elidirse.

Criterios para considerar como para en calidad de cuantificador evaluativo

1) A nivel semántico se evalúa una cantidad como excesiva o insuficiente para alcanzar un objetivo.

2) A nivel formal estas estructuras se relacionen con los cuantificadores mucho (muy) о росо.

Criterios para considerar la pauta como mucho en calidad de introductor de enunciados aproximativos

1) Se quiere expresar una cantidad como una valoración aproximada del hablante. Mediante ellas se quiere significar que se trata de una cantidad superior a la real.

Criterios para considerar la pauta asi como en calidad de introductor de oraciones temporales

1) Como introduce información temporal cuando es equivalente al adverbio de tiempo cuando o la construcción tan pronto como.

2) Cuando como introduce oraciones temporales, siempre aparece con el antecedente así, el cual no puede elidirse sin cambiar el sentido semántico de la oración. 3) Se colocan en relación dos situaciones paralelas. 